\title{
Studies Regarding the Tribological Behavior of Two Polymeric Materials
}

\author{
IVONA CAMELIA PETRE, ELENA VALENTINA STOIAN*, MARIA CRISTIANA ENESCU* \\ Valahia University of Targoviste, Faculty of Materials Engineering and Mechanics, 13 Sinaia Alley, 130004, Targoviste, Romania
}

\begin{abstract}
Due to the good properties related to wear resistance and vibration absorption capacity, the polymeric materials successfully replace the metallic materials. These are used in the production of sliding motion couples. Rubbing couples whose materials are polymer / steel based are of particular interest for technical use. In order to operate any mechanical system with sliding motion at optimum parameters, the indication of tribological characteristics for the materials of the frictional coupling is a convenient means of characterizing faster the tribological behavior, when the working conditions are modified. In this paper it is analyzed by the help of an experimental study, the factors affecting the wear of a coupling of polymer material/steel. Materials subjected to tribological analysis are polymeric materials, such as polyamide (PA) and polytetrafluoroethylene (PTFE) in contact with a metallic material (steel). The connection between the friction coefficient and the operating parameters (load, speed) and the rate of wear of these materials under experimental conditions will be established. Testing of the two materials was made on a pine stand on disc. The tribological tests were performed varying load and speed for a given length of friction, traveled pine. The wear of the two materials tested for the experimental conditions was measured. The experimental researches were carried out in dry friction conditions.
\end{abstract}

Keywords: polymer, tribological behavior, coefficient of friction, wear rate

\section{Introduction}

The polymeric materials used in making couplings with sliding movement play a crucial role in future technological development in all industrialized countries. Their use in the machine building industry has reached an assimilation rate of about $44 \%$ of the total raw material worldwide.

The behavior of the materials in a mechanical system, under the action of the working factors (load, speed, temperature, lubrication etc.) influences the good functioning of them. In order to operate the mechanical system at optimal parameters, the indication of the tribological characteristics for the materials of the frictional coupling (friction coefficient, wear intensity, wear resistance, etc.) are a convenient way to characterize the tribological behavior faster, when the working conditions are modified [1-10].

The progress in understanding the tribological behavior of polymeric materials involves multiple experimental researches, until their introduction and use in the realization of different machine elements.

\section{Materials and methods}

\subsection{Methods for determining tribological characteristics}

Tribological behavior of polymeric materials, as mechanisms of their friction and wear, is more complex than for other pairs of materials (metal/metal, metal/ceramic), they respecting the "laws of friction". This is due to the properties that vary during the operation of the coupling [11-14].

Unlike rigid friction material (metal or non-metal) friction polymer material is characterized by changes in the viscoelasticity. The phenomenon of hysteresis of the material varies with the speed of sliding friction torque and temperature. Variation of these parameters can explain the influence of operating conditions on tribological behavior [15-17].

*email: elenastoian22@gmail.com,cristiana_enescu@yahoo.com 
Knowing these changes that occur at the level of the surfaces of the rubbing surfaces in contact leads to the need to test polymeric materials under conditions as close as those of industrial applications.

Wear tests for sliding friction couples are generally performed on pin-on-disc devices. The measured data allow for determining tribological characteristics, with the following equations:

- coefficient of friction $(\mu)$ :

$$
\mu=\frac{F_{n}}{F_{f}}
$$

- specific wear rate:

$$
k=\frac{U_{v}}{F_{n} \cdot L_{f}}\left[\frac{m m^{3}}{N \cdot m}\right]
$$

where: $L_{f}$ is the path length of frictional motion $[\mathrm{mm}]$;

$F_{n}$ is the normal force in $\operatorname{contact}[N]$;

$U_{v}$ is the volume of worn material $\left[\mathrm{mm}^{3}\right]$, where $U_{v}=m / \rho$;

$m$ mass of worn material, during sliding $[g]$;

$\rho$ material density $\left[\mathrm{g} / \mathrm{mm}^{3}\right]$;

$F_{f}$ is the friction force $[N]$.

Specific wear is a characteristic of the pair of materials involved in the sliding motion (refers to the conditions of the experiment). This allows the choice of an optimal pair of materials that work in the same stress conditions $[4,5,8]$.

\subsection{The selection of materials}

The tribological contact type (polymer / steel) is of particular interest for using in technical systems. In this context, there are polymers that have valuable tribological properties and most research is focused on finding the best performers. For this study, two types of polymeric materials frequently used in the frictional couples with sliding motion of the different mechanical systems were selected.

The samples were made from commercially available elements of full rods. They were machined so that they could be mounted in the tribometer clamp.

PTFE, is well known fluoropolymer in the case of mechanical systems that operate under low stresses and high temperatures. The mechanical properties of PTFE are modified by the addition of: glass fibers [18], glass beads [19], graphite, ceramic, bronze, $\mathrm{MoS}_{2}$. The introduced compounds allow for improving certain mechanical and tribological characteristics, such as: compressive power, wear resistance, thermal conductivity, or reducing the tendency to elongation. In this way, parts are obtained that admit considerable improvements both in design and the operational use (eg: sliding bearings, pump bodies).

PA6 is a polyamide that has an excellent combination of mechanical properties, rigidity, hardness, mechanical damping and wear resistance. In combination with graphite and $\mathrm{MoS}_{2}$ for reducing friction and wear, is used in mechanical systems with slow movements and high loads. It can have, in this additived version, a low coefficient of friction (lower with 50\%) and a better wear resistance.

Polyamide 6 is widely used as a material for various applications, such as sliding couples. It has an exceptional combination of properties, such as high hardness, tensile strength and abrasion resistance, low density and friction coefficient and it is quite easy to process.

In order to improve the mechanical properties and the tribological behavior, these materials have been reinforced with some micro- and nano- particles or fibers, such as $\mathrm{CuS}, \mathrm{CuF}_{2}, \mathrm{CuO}, \mathrm{PbS}, \mathrm{CaO}, \mathrm{CaS}$ and carbon fibers that are beneficial in reducing the wear rate of polyamides.

The chemical structure of tested materials is shown in Figure 1. 


\begin{tabular}{|c|c|}
\hline$\left[-\mathrm{CF}_{2}-\mathrm{CF}_{2}-\right]_{n}$ & {$\left[-\mathrm{NH}-\left(\mathrm{CH}_{2}\right)_{5}-\mathrm{CO}-\right]_{n}$} \\
\hline Polytetrafluoretylene (PTFE) & Polyamide(PA6) \\
\hline
\end{tabular}

Figure 1. The chemical structure of the tested materials

The physico-mechanical characteristics (properties) of the two polymers are presented in table 1 [15].

Table 1. The physico-mechanical characteristics

\begin{tabular}{|c|c|c|c|}
\hline Property & Units of measure & PTFE [] & PA6 [] \\
\hline Density & $\mathrm{Kg} / \mathrm{m}^{3}$ & $2.17 .10^{3}$ & $1.13 .10^{3}$ \\
\hline Modulus of elasticity & $\mathrm{GPa}$ & 0.49 & 2.95 \\
\hline Tensile strength & $\mathrm{MPa}$ & 24 & 100 \\
\hline Elongation at break & $\%$ & 300 & 60 \\
\hline Flexural strength & $\mathrm{MPa}$ & 33 & 91 \\
\hline Thermal conductivity & $\mathrm{W} /(\mathrm{mK})$ & $95.10^{-6}$ & $66.10^{-6}$ \\
\hline Maximum work temperature & ${ }^{\circ} \mathrm{C}$ & 290 & 110 \\
\hline Dielectric constant & - & 2.1 & 4.5 \\
\hline
\end{tabular}

\subsection{Experiment conditions}

In the sliding contacts, it was found that the coefficient of friction varies according to the duration of the friction and also differs due to operating conditions (normal load, sliding speed).

The experiments were performed on the pin on disc test tribological stand. Figure 2 shows the principle diagram of the device [16]. The pin was made of tested polymeric materials, and the disc was made of non-alloy structural steel S235, SR EN 10025-1:2005

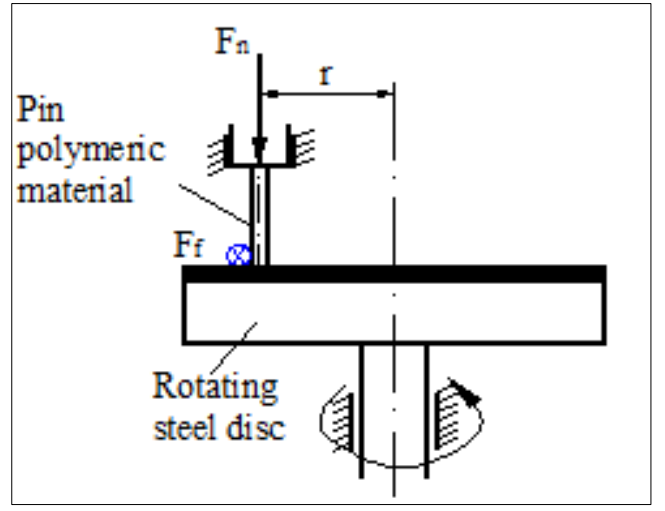

Figure 2. Pin / disc stand operating diagram

The contact surface of the pine was $8 \mathrm{~mm}^{2}$ from and the disk was processed with a $R a 1,6$ roughness. The temperature at which the experiments were carried out was the ambient temperature. The authors realized two experiments under the same conditions and their average values for the parameters of interest are represented in Figures 3-6. The experiments were done for speeds of $\mathrm{v}_{1}=1 \mathrm{~m} / \mathrm{s}$ and $\mathrm{v}_{2}=2 \mathrm{~m} / \mathrm{s}$ and normal force loads of $\mathrm{F}_{\mathrm{n} 1}=10 \mathrm{~N}$ and $\mathrm{F}_{\mathrm{n} 2}=20 \mathrm{~N}$. Each test was done under the conditions of dry friction, the samples were cleaned and degreased for each experiment. The pin was positioned on the disk for each experiment at a radius $\mathrm{r}=100 \mathrm{~mm}$. The coefficients of variation of the measurements for the same test conditions were $c_{v}=0.94$ for PTFE and $\mathrm{c}_{\mathrm{v}}=0.93$ for PA6.

In order to measure the wear, the samples were weighed at the beginning and the end of each experiment. The wear of the pairs of materials under analysis were evaluated for loads of $\mathrm{F}_{\mathrm{n} l}=10 \mathrm{~N}$, $\mathrm{F}_{\mathrm{n} 2}=20 \mathrm{~N}$ and slip speed $\mathrm{v}_{1}=1 \mathrm{~m} / \mathrm{s}$. Wear assessment was done after 60 min of operation. 


\section{Results and discussions}

In sliding motion couples, the coefficient of friction varies depending on the duration of the friction. Variations are also given by the normal load and the sliding speed. In this research, the authors have been observed the variation coefficient of friction during slipping couplings of mentioned polymer materials and steel.

Figures 3 and 4 show the variation of the friction coefficient during the sliding of the normal load $\mathrm{F}_{\mathrm{n} 1}=10 \mathrm{~N}$ and $\mathrm{F}_{\mathrm{n} 2}=20 \mathrm{~N}$ speed $\mathrm{v}_{1}=1 \mathrm{~m} / \mathrm{s}$ different for the two types of materials.

Figure 3 reveals that the variation coefficient of friction PTFE are relatively low and decline during sliding. For PA6 polymers there is an increase in the friction coefficient in the first part of the sliding time, after which the values of the friction coefficient begin to decrease and stabilize as a value. This is due to the transfer of PA6 material to the steel disk.

In figure 4 when the normal pressing force increased $\mathrm{F}_{\mathrm{n} 2}=20 \mathrm{~N}$, the same tendency of evolution of the friction coefficient for the two materials is observed.
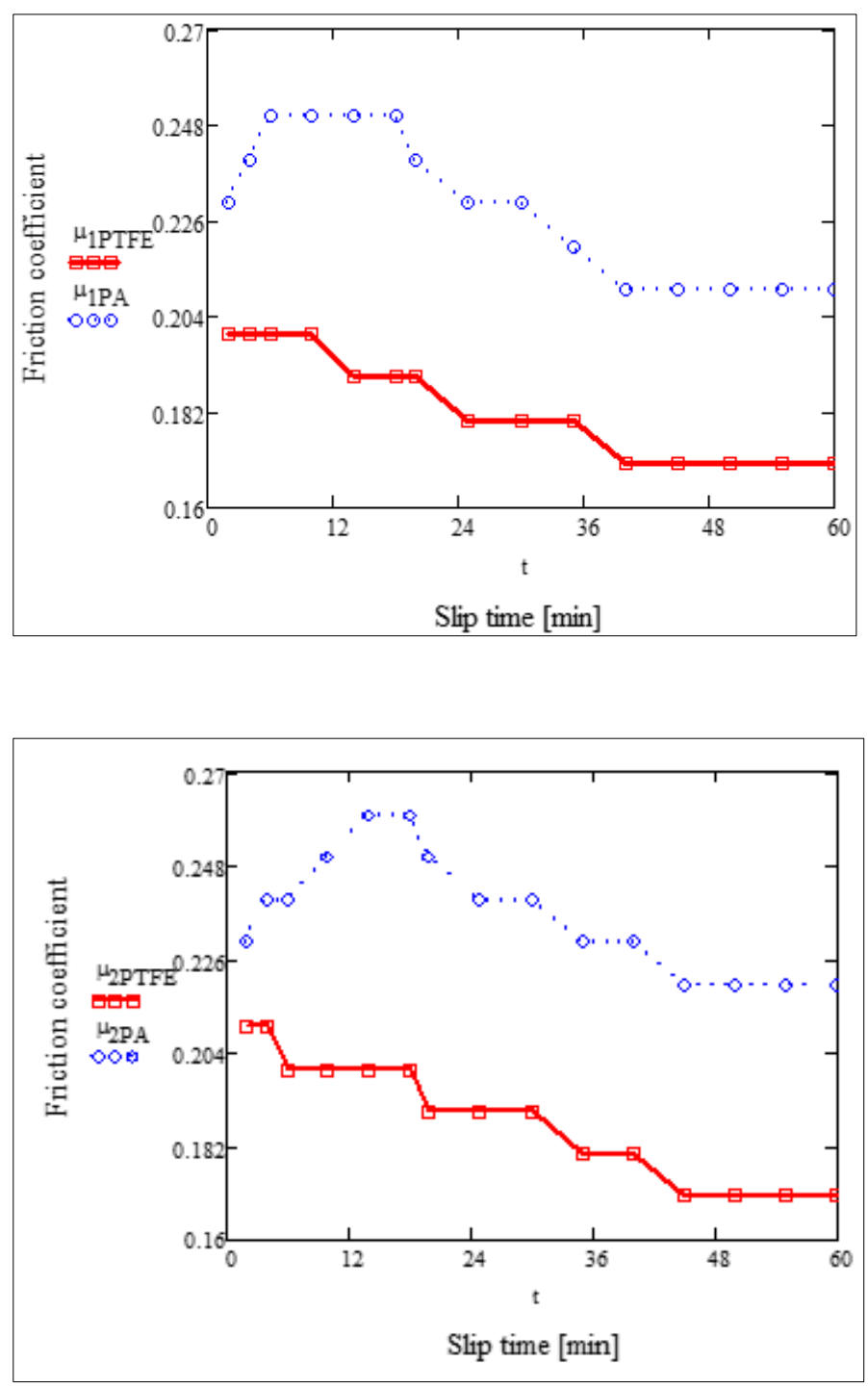

Figure 3. Variation of the friction coefficient for a sliding speed of $v_{1}=1 \mathrm{~m} / \mathrm{s}$, at a normal

loading force $F_{n 1}=10 \mathrm{~N}$, for the two materials sliding against steel

Figures 5, 6 and 7 show the variation of the friction coefficient with the slip duration for the speeds $v_{1}=1 \mathrm{~m} / \mathrm{s}$ and $v_{2}=2 \mathrm{~m} / \mathrm{s}$ at a load $F_{n 1}=10 \mathrm{~N}$ for the three types of materials sliding against steel. 


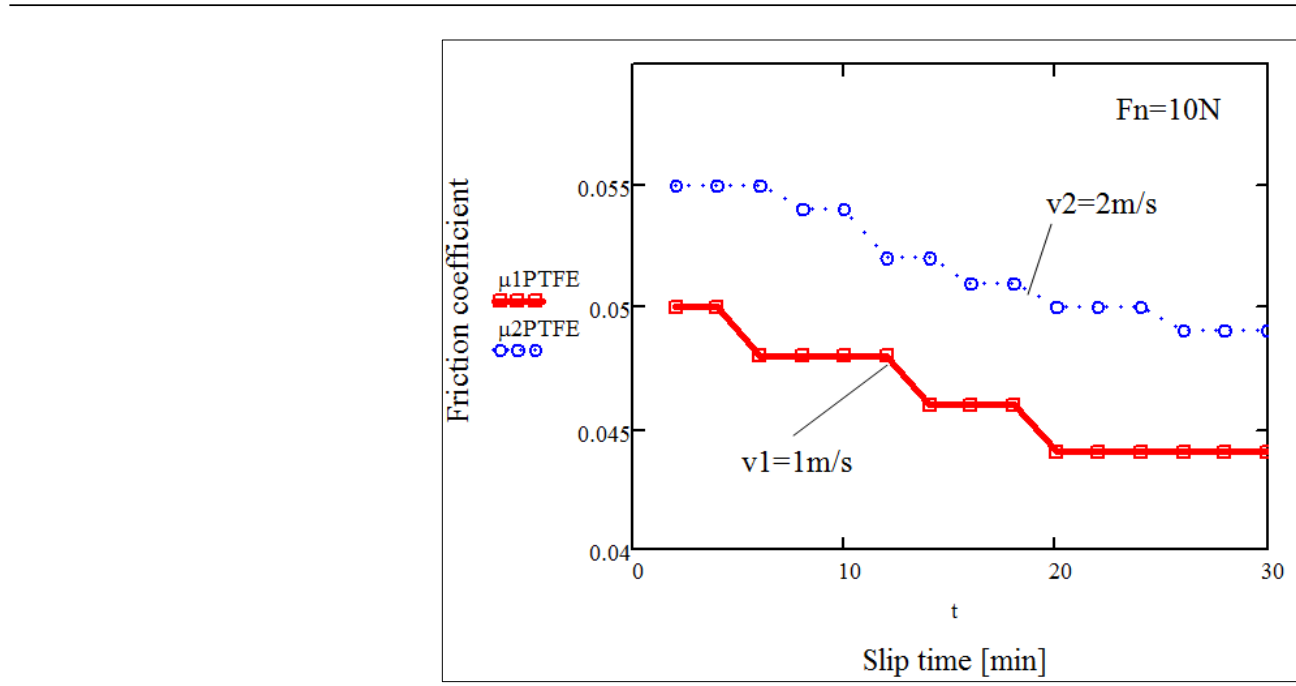

Figure 5. Variation of the coefficient of friction for a load $F_{n 1}=10 \mathrm{~N}$ at different sliding speeds for

PTFE sliding against steel

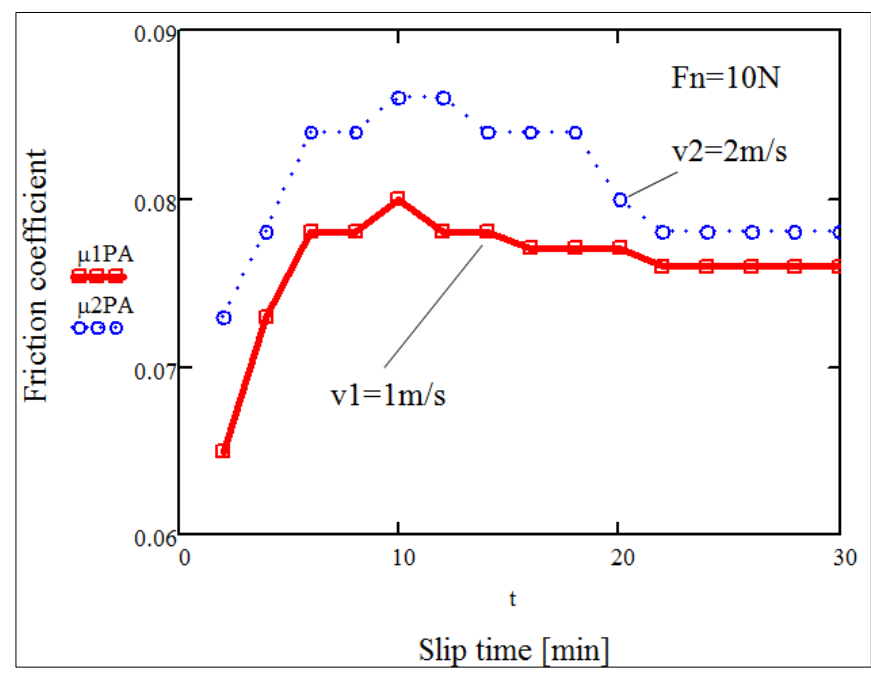

Figure 6. Variation of the coefficient of friction for a load $F_{n 1}=10 \mathrm{~N}$ at different sliding speeds for PA6 sliding against steel

It is noticeable from Figures 5 and 6 the variation of the coefficient of friction with the speed, during the slip. Increasing the sliding speed, the values of the coefficient of friction increases. It is noted that for PA6 the values of the coefficient of friction increase in the first part of the slip, followed by a stabilization of its values.

Figure 7 shows the wear rate for the two materials, after sliding on steel, as a function of loading $F_{n 1}=10 \mathrm{~N}$ and $\mathrm{F}_{\mathrm{n} 1}=20 \mathrm{~N}$ for a sliding speed of $v_{1}=1 \mathrm{~m} / \mathrm{s}$. It is worth noticing that the wear rate of PA6 is much lower than for PTFE. The last one has a higher wear rate with increasing load. 


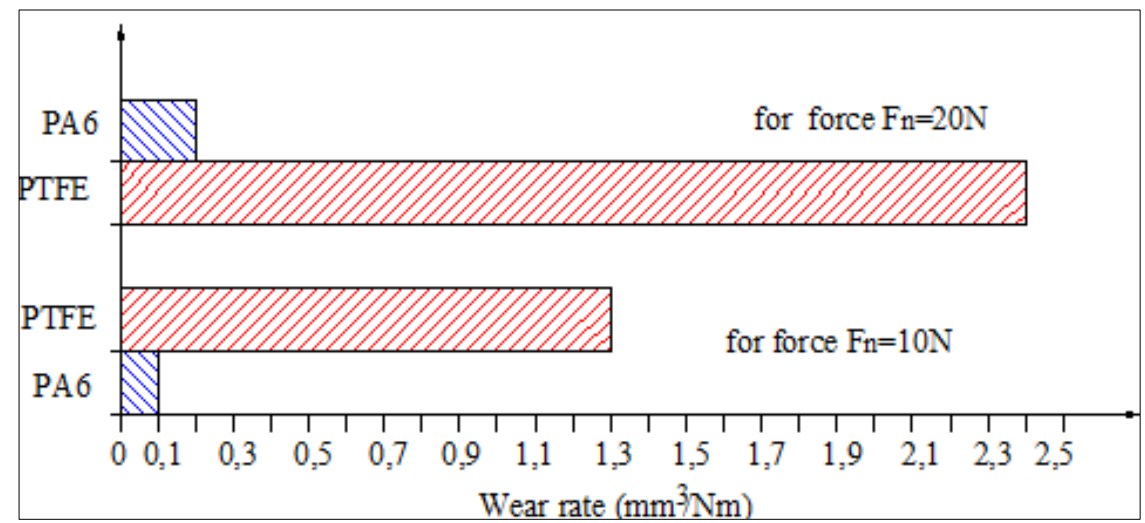

Figure 7. Wear rate as a function of normal load for tested materials, sliding velocity $\mathrm{v}_{1}=1 \mathrm{~m} / \mathrm{s}$

Following the tests made on the two materials, it is found that although PTFE has a lower coefficient of growth, its wear rate is higher than PA6 for the same operating conditions.

\section{Conclusions}

Friction and wear of polymeric materials is significantly affected by abnormal load and sliding speed. The size of the coefficient of friction depends on the materials chosen and the pair of operating parameters.

The comparative study carried out between PTFE and PA6 materials in the same experimental conditions shows that:

- PTFE has a value of coefficient of friction lower than that of PA6 and its evolution over time is relatively constant;

- PA6 in the first part has a pronounced increase slip friction coefficient value after it stabilizes. This is due to the transfer of polymeric material on the surface of the disk;

- wear PTFE is higher than that of PA6 for the same stress conditions.

In other words, the designer interested in having a low friction coefficient, PTFE could select instead of PA6.

The experimental results obtained correspond to the research found in the specialized literature [19, $20,23,24]$. They can be used in the future to design different components of mechanical tribosystems.

Researchers can use these results to design high performance mechanical systems to improve the various mechanical processes in which friction and wear phenomena occur.

\section{References}

1. 1 TABOR, D. Friction, Lubrication and wear, W Source: Mechanical design handbook (2003).

2. BHUSHAN, B. Introduction to tribology, Second edition, A John Wiley\& Sons, Ltd., Publication (2013).

3. FRIEDRICH, K., Polymer composites for tribological applications, Advanced Industrial and Engineering Polymer Research, 1 (1), 2018, 3-39.

4. PETRE I, POPESCU I.N., UNGUREANU D. N., Aspects regarding the tribological behavior of Turcite and Relamid polymeric materials, in sliding motion couples, Mater. Plast., 56(1), 2019, 5558.

5. PETRE I., ENESCU M. C., STOIAN E. V., Research Regarding the Evolution of Friction Coefficient in a Friction Torque Like a Plastic Material / Steel for Different Parameters, Revista Mater. Plast., 56(4), 2019, 918-922

6. DORIN RUS, LUCIAN CAPITANU, LILIANA-LAURA BADITA, A qualitative correlation between friction coefficient and steel surface wear in linear dry sliding contact to polymers with SGF, Friction, 2(1), 2014, 47-57. 
7. POPESCU I.N., ZAMFIR S., ANGHELINA V.F., RUSANESCU C.O., Processing by P/M route and characterization of new ecological Aluminum Matrix Composites (AMC), International Journal of Mechanics, 4(3), 2010, 43-52.

8. PETRE I., Wear Model of Sliding Motion Flat Surfaces Used in Mechanical Engineering, Applied Mechanics and Materials, 658, 2014, 345.

9. WANG, Q., XUE, Q., LIU, W., CHEN, J., The friction and wear characteristics of nanometer SiC and polytetrafluoroethylene filled polyetheretherketone, Wear, 2000, 243, 140-146.

10. BAHADUR, S., POLINENI, V. K., Tribological studies of glass fabric-reinforced polyamide composites filled with $\mathrm{CuO}$ and PTFE, Wear, 1996, 200, 95-104.

11. STUART, B. H., Tribological studies of poly(ether ether ketone) blends Tribology Int., 31, 1998, 647-651.

12. PETRE, I., TUDOR, A., Friction and wear model for polymer and cast iron couple, The Annals of University "Dunărea De Jos" of Galaţi Fascicle VIII, Tribology 2003, 107-111.

13. OSCAR, O.M., BROSTOW, W., BUCHMAN, ELI. Wear Resistance and Wear Mechanisms in Polymer + Metal Composites, Journal of Nanoscience and Nanotechnology, 10(12), 2010, 82548259

14. D.KOPELIOVICH, Tribology of polymers, https://www.substech.com/dokuwiki/doku.php?id=tribology_of_polymers.

15. PAVELESCU D., MUSAT M., TUDOR ,A. Tribologie, EDP Bucuresti, 1977

16. NURUZZAMAN D. M., CHOWDHURY M. A., Friction and Wear of Polymer and Composites, DOI: $10.5772 / 48246,2012$.

17. CRUCEANU, C., CRACIUNA, C., Aspects Regarding the Braking Capacity of Composite Brake Shoes for Railway Vehicles, Mater. Plast., 56(1), 2019, 18-21.

18. DELEANU, (TOMESCU) L., Contribuţii la studiul stratului superficial al compozitelor cu matrice de politetrafluoretilenă pe tribomodele de alunecare, „Dunărea de Jos” University of Galati, 1999.

19. GEORGESCU, C., The evolution of the superficial layers in wear and friction processes involving composite materials with polybutylene terephthalate, „Dunărea de Jos” University of Galati, 2012.

20. ***https://www.substech.com/dokuwiki/doku.php?id=thermoplastic_polytetrafluoroethylene_ptfe.

21. ***https://www.substech.com/dokuwiki/doku.php?id=thermoplastic_polyamide nylon_6.

22. PETRE I.C., CATANGIU, A., POPESCU, I.N., UNGUREANU, D. N., NEGREA, A., POINESCU, A.A., ENESCU, M.C., STOIAN, E.V., DESPA, V. Tribometric device for determining friction forces and friction coefficients in the case of dry friction materials, The Scientific Bulletin of Valahia University, Materials and Mechanics, 16(15), 2018, 17-20.

23. LATES, M., T. VELICU, R. GAVRILA, C.C., Temperature, Pressure, and Velocity Influence on the Tribological Properties of PA66 and PA46 Polyamides, Materials 2019, 12, 3452; doi:10.3390/ma12203452.

24. KALÁCSKA G., An engineering approach to dry friction behaviour of numerous engineering plastics with respect to the mechanical properties, eXPRESS Polymer Letters Vol.7, No.2 (2013) 199-210. Polymer Letters Vol.7, No.2 (2013) 199-210

Manuscript received: 16.04 .2020 